\title{
Recurrent Malignant Ovarian Brenner Tumor
}

National Cancer Institute

\section{Source}

National Cancer Institute. Recurrent Malignant Ovarian Brenner Tumor. NCI Thesaurus.

Code C153818.

The reemergence of malignant ovarian Brenner tumor after a period of remission. 